EKSAKTA Vol. 12 No. 1, 1-5

\title{
Screening of Secondary Metabolites Compounds in Stem Bark of Frangipangi (Plumeria alba) and Toxicity Test on Shrimp Larvae (Brine Shrimp Lethality Test)
}

\author{
Santi Nur Handayani dan Moch. Chasani \\ Program studi Kimia Jurusan MIPA FST UNSOED \\ santinurhandayani@yahoo.com
}

\begin{abstract}
Frangipani is a plant belonging to the family Apocynacea and potential for development as anti-cancer drug material. Content of secondary metabolites, anti-cancer compounds from frangipani (Plumeria alba) steam bark, especially it has not been made. This research aims to identify compounds secondary metabolites from frangipani steam bark extract potential for development as anti-cancer drug material.

Steps undertaken in this study include: Extraction of secondary metabolites with frangipani stem bark maceration method of storey with n-hexane, chloroform, ethyl acetate, and ethanol. Each tested extracts obtained using prawn shrimp toxicity A. salina Leach and continued with the testing of secondary metabolites using color reagents. fraction extract has potential as an anti-cancer drugs is purified using gravity column chromatography technique with elusi gradient technique using a solvent mixture nhexane:ethyl acetate hen conducted toxicity tests followed by identification using GC-MS

Extraction results obtained by the four extracts namely: $n$-hexane extract $\left(\mathrm{E}_{1}\right)$ is positive flavonoid groups, chloroform extract $\left(\mathrm{E}_{2}\right)$, ethyl acetate extract $\left(\mathrm{E}_{3}\right)$ and ethanol extract $\left(E_{4}\right)$ is positive for secondary metabolite groups flavonoid and alkaloid. Toxicity test results obtained $\mathrm{LC}_{50}$ values respectively participated: $973.7 \mathrm{ppm}\left(\mathrm{E}_{1}\right), 451.35 \mathrm{ppm}$ $\left(\mathrm{E}_{2}\right), 112.557 \mathrm{ppm}\left(\mathrm{E}_{3}\right)$, and $637.50 \mathrm{ppm}\left(\mathrm{E}_{4}\right)$.
\end{abstract}

Keywords: Plumeria alba, secondary metabolite, toxicity test, and A. salina Leach 